\title{
A Web Designed for Helping Citizen to Make an Informed Decision of Energy Policy
}

\author{
Jeng-Chung Chen, Shin-Cheng Yeh, and Han Chen
}

\begin{abstract}
Since the policy of "no-nuclear community" was announced, Taiwan has been on the one-way destined for a change of energy structure. But debates about energy structure never stop here. A team composed of four Taiwan's universities was born by the duty of finding a way to help citizen to make an informed decision of energy policy and created Taiwan Energy Policy Educational Model (TEPEM). A web with knowledge map of energy, role-playing game, and decision support by TEPEM was developed for a series of teaching tests in this study. As a result, knowledge map is useful to improve the realization of energy. Most decision makers in this study also confirm the necessity of decision support by TEPEM while making a choice of energy policy. But using role-playing game to promote each other's communication on energy policy is in vain during these tests. A real talk would be more useful to vanish the gap than a visual role-playing game.
\end{abstract}

Index Terms-Decision making, energy policy, model, web.

\section{INTRODUCTION}

IEA had called on a necessary change of current energy structure due to mitigating Greenhouse Gases (GHGs) emission and climate change [1]. Adjusting energy structure is particularly imperative in Taiwan due to its high dependency on the imported energy. But debates about energy structure never stop here. According to the past records, nuclear power is the cheaper and cleaner one of the main energy sources in Taiwan. But Taiwan is a crowded island with a population of 23.1 million people. People always worry nuclear disaster like Fukushima accident and the voice of stopping nuclear power has been continuing for more than three decades. Eventually government announced a "no-nuclear community" policy and set a target of no-depending nuclear power after the year of 2025. At the same time, government also announced its GHGs reduction targets and schedules as "By 2050, the annual GHGs emission level should be no larger than $50 \%$ of the level in 2000 ". How to build new energy structure become a big challenge to the decision maker who simultaneously faces the demand of industry and the appeal from citizen. Such a dilemma not only challenges the decision maker in Taiwan

Manuscript received December 17, 2017; revised January 23, 2018. This work was supported in part by the Taiwan Ministry of Science and Technology under Grant NSC101-3113-S-003-002.

J. C. Chen is with the Department of Environmental Engineering and Science, Fooyin University, Kaohsiung, Taiwan 83102, R.O.C. (e-mail: p1007@fy.edu.tw).

S. C. Yeh is with the Graduate Institute of Environmental Education, National Taiwan Normal University, Taipei Taiwan 11677, R.O.C. (e-mail: scyeh@ntnu.edu.tw).

H. Chen is with Fooyin University, Kaohsiung, Taiwan 83102, R.O.C. (e-mail: lon840529@yahoo.com.tw). but also everywhere in the world. For this concern, many researchers proposed the optimal energy structure from the thinking of supply, cost and risk. For examples, a research discussed the optimal scale of biofuel energy applications at different fixed and variable costs [2], someone tried to propose a proper allocation of energy appliances and a selection of fuels at discussing modernization of Poland's energy system [3], someone used an optimal model with social acceptance, system reliability, energy demands, and renewable energy development to evaluate the energy structure for India [4], and a multi objective programming technique was used to evaluate the cost and the environmental impacts while deciding the expansion of regional power systems in far west Texas [5]. The above researches concluded that decision-making of energy structure is not an easy job and covers a lot of knowledge. U.S. Department of Energy had a statement that individuals without a basic understanding of energy, energy sources, power generation, energy use and conservation cannot make informed decisions on topics ranging from smart energy use at home to national energy policy [6].

Studies about energy issues have been flourishing since the 1970s energy crisis. Geller was one of the pioneers to evaluate people's attitude, knowledge, and intention to energy conservation [7]. In order to determine whether energy education can influence students, "energy literacy" was used to term the individual's understanding of the reasons for energy conservation, the need of seeking alternative energy, and the duty of caring environmental impact [8]. NEETF made a survey on young adults over the age of 18 and only $12 \%$ of them passed a basic energy quiz [9]. It revealed that most Americans are ill-prepared to think energy problems because they largely lack energy-related knowledge [10]. Right now the portable devices with service supported by cloud computing has created the new chance of making smart decision of energy policy. People are able to access information all the time within reach of a wireless network [11], [12]. Thus we aimed at discussing what kind of information is useful to support people's judge about energy policy. A web with knowledge map of energy, role-playing game, and decision support by TEPEM was therefore created to carry out a series of teaching tests in this study. Then we gathered several college students to experience our web and studied their behavior during making decision after they had one-hour exploration of the web's content.

Due to energy as a public policy, this study also observed how to form a consensus of energy policy from different decision-makers. People must recognize that they have a common problem and start to negotiate to develop a shared definition of the problem involved [13]. Someone proposed a 
way that let people to see the collective consequences of their individual decisions and then initiated a negotiation between them [14]. As fast growing of Internet, communication via IT devices has become a major way of exchanging thinking at society. We supposed that on-line game is able to make players easily communicate each other. Raiyn gave us an e-society cognitive platform which is able to help people improving their ability of communication [15]. This inspired us to create a web which let user discover the difference of view through a role-playing game. Three activities binding with our web were used to evaluate the effects of knowledge map of energy, role-playing game, and decision support by TEPEM. We designed a questionnaire of examining energy literacy to verify the effects of our web. As a result, knowledge map is useful to promote the realization of energy issues. But the attitude on communicating people with respect to energy issues seems to be 'no significant difference'. Even with the aid of new IT technology, to speak out the thinking about public policy is still difficult to people. Decision makers need a real talk to vanish the gap not a visual role-playing game. On the contrary, making decision with support by TEPEM or not is 'significant difference'.

\section{ARChiteCtURE OF WeB}

\section{A. Knowledge Map}

Concept map is able to catch a long time retention of the information in students' memories [16]. A concept map looks like a network in which all concepts would be networked together. This technique was developed by Dr. Novak [17]. Dubberly suggested using concept maps to represent factors that influence the development process of product, software and services [18]. Right now more and more knowledge maps constructed by the technique of concept map are often used as learning materials [19]. In this study, we made a concept map of energy structure as Fig. 1 and then transfer it as a knowledge map on web. This web is composed of several hierarchical webpages in which users can expand the holistic knowledge of each energy only by touching the tags which they want to know.

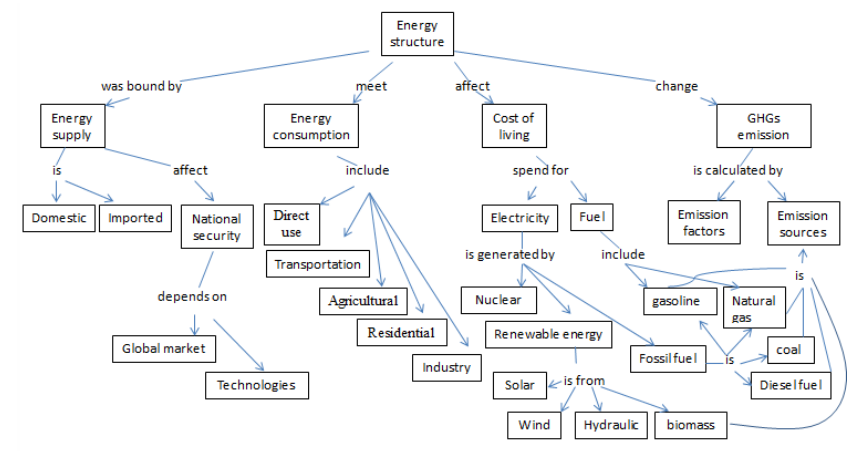

Fig. 1. Knowledge map of energy structure.

\section{B. Role-Playing Game}

A role-playing game derived by a scenario in which there are a lot of characters with different views on energy policy. In this study, we created three characters: boss (character I), mother (character II), and driver (character III) and gave them a personality according to the interview with someone who really is (Fig. 2). This game will let users pay attention to different voices around us. When people are willing to realize and accept different views on energy policy, a consensus might be easily formed. Thus we supposed the following hypothesis:

Hypothesis-1: Users pay more attention to different views and will be more willing to discuss with people after participating in role-playing games.

Hypothesis-2: This game let users consider different views when making their choice of energy policy.

Hypothesis-3: The user will like to negotiate and coordinate with other people when they face different voice on energy policy.

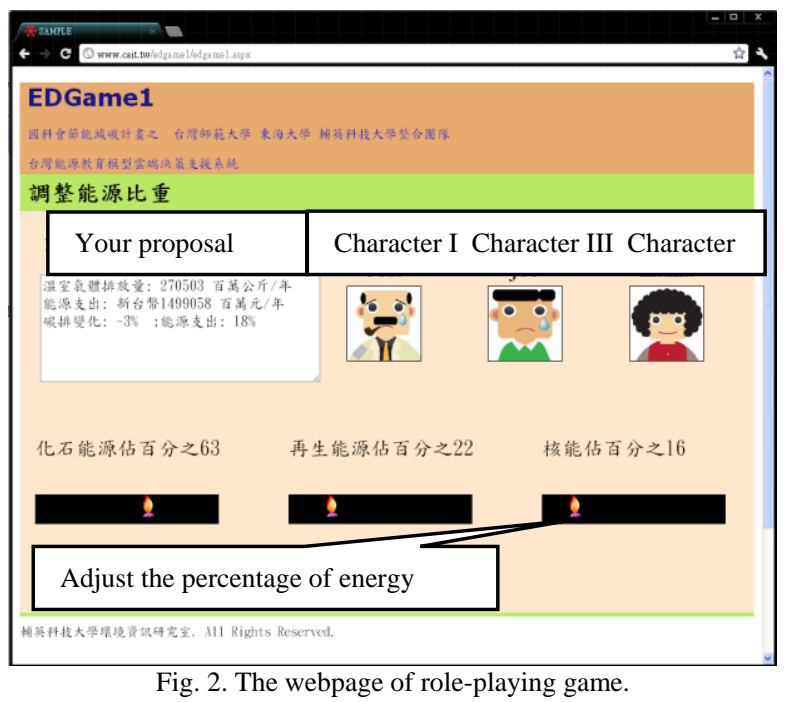

\section{Decision Support by TEPEM}

Using computer analysis is able to save the time of try-and-error and lets users easily work out a wise allocation of energy sources. So we created a web-enabled decision support by TEPEM which works as a web service of Lindo API. LINDO is a popular software to optimization analysis and provides several solvers to handle the inside calculation. This study adopted REST as the way of building client-server applications to fulfill cloud computing. People simply access this decision support via Internet and access it anywhere. IT technologies including HTML5, ASP.NET, CSS, AJAX, and JSON, were used in this decision support.

TEPEM can serve multiple clients at the same time and play as a communication platform for achieving consensus in decision-making of energy structure. There are six scroll bars in the webpage to adjust the changing rates of oil price, the target of carbon reduction, annual consumptions of electricity, oil, coal, and natural gas. After sending the above inputs cons, the message "you got the optimal solution " will promptly come out if it exists, sometimes there is no answer for your inputs (shown as Fig. 3). As you see in Fig. 3, a case of the oil price being annually risen up by $1 \%$ o and the carbon reduction of $20 \%$ off at the target year of 2030 obtains a suggestion of energy structures composed of $37.1 \%$ as coal, $29.5 \%$ as gasoline and diesel fuel, $12.5 \%$ as natural gas, $11.2 \%$ as renewable energy, and $9.7 \%$ as nuclear power. We had the following hypothesis: 
Hypothesis-4: After experiencing decision support, users will pay more attention to the trend of renewable energy.

Hypothesis-5: Decision support enhances user to understand Taiwan's situation of dependence on imported energy.

Hypothesis-6: Decision support help user to get a better understand of the cost due to choose renewable energy.

Hypothesis-7: Decision support help user to get a better understand of the correlation between energy structure and GHGs emissions.

Hypothesis-8: Decision support help user realizing what is able to meet the goal of GHGs reduction.

Hypothesis-9: Decision support help user realizing the necessity of renewable energy in order to achieve a specific goal of GHGs reduction.

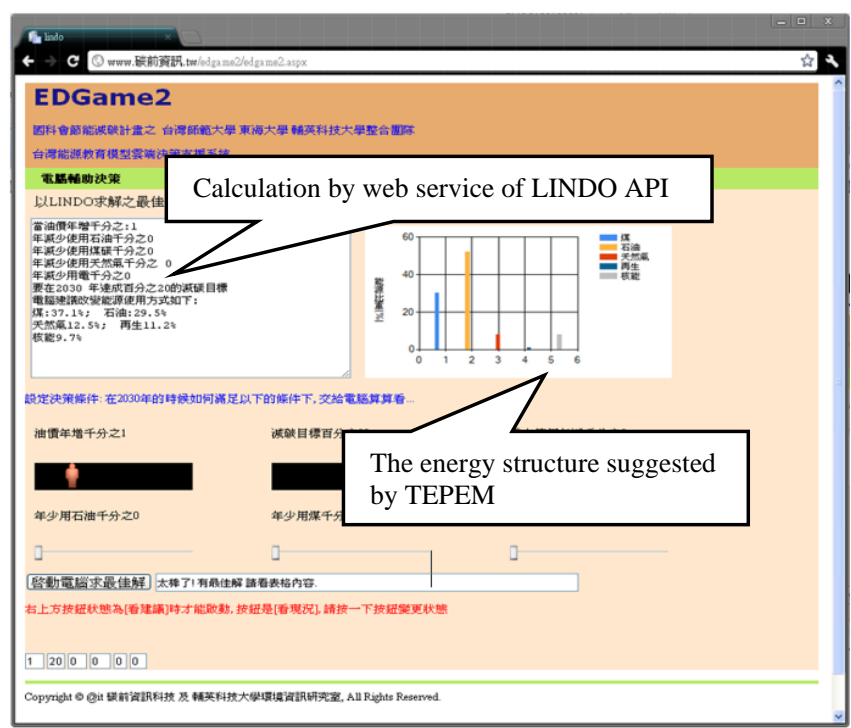

Fig. 3. The webpage of decision support by TEPEM

\section{METHODS}

\section{A. Questionnaire}

We designed a questionnaire of examining energy literacy to quantify the effects of our web. U.S. Department of Energy outlined five characteristics of energy-literate citizen as Table 1 [6]. After a process of pre-exam, we picked up 23 questions for evaluating each index of Table I (in which Cronbach's $\alpha$ of 23 questions is 0.83 ). A Likert scale with 5 levels was used to let the subjects evaluate these questions.

TABLE I: CHARACTERISTICS OF ENERGY-LITERATE PERSON AND QUESTIONNAIRE DESIGN

\begin{tabular}{cl}
\hline \hline Indexes & \multicolumn{1}{c}{ Questions } \\
\hline & $\begin{array}{l}\text { 2-1 Increasing the ratio of solar energy use can } \\
\text { effectively reduce greenhouse gas emissions. }\end{array}$ \\
\cline { 2 - 2 } $\begin{array}{l}\text { 2-3 Using natural gases as the fuel for power } \\
\text { generation does not generate greenhouse gas } \\
\text { emissions }\end{array}$ & $\begin{array}{l}\text { 2-5 I do not think that a higher ratio of nuclear } \\
\text { energy use can reduce greenhouse gas emissions in } \\
\text { can think in terms } \\
\text { of energy systems }\end{array}$ \\
\cline { 2 - 2 } $\begin{array}{c}\text { Taiwan. } \\
\text { 2-6 I believe that increasing the ratio of fossil fuel } \\
\text { use increases greenhouse gas emissions. }\end{array}$ \\
$\begin{array}{c}\text { 2-2 More than 99\% of Taiwan's energy supply is } \\
\text { knows how much } \\
\text { energy he or she } \\
\text { uses, for what, and }\end{array}$ & $\begin{array}{l}\text { 3-3 I understand the potential development trends } \\
\text { of various renewable energies. }\end{array}$ \\
\hline
\end{tabular}

\begin{tabular}{|c|c|}
\hline $\begin{array}{l}\text { where the energy } \\
\text { comes from }\end{array}$ & $\begin{array}{l}\text { 2-4 The power supply in Taiwan relies primarily on } \\
\text { nuclear energy. }\end{array}$ \\
\hline \multirow{6}{*}{$\begin{array}{l}\text { Index } 3 \\
\text { can assess the } \\
\text { credibility of } \\
\text { information about } \\
\text { energy }\end{array}$} & $\begin{array}{l}\text { 3-1 Among all fossil fuels, petroleum yields the } \\
\text { highest greenhouse gas emission coefficient. }\end{array}$ \\
\hline & $\begin{array}{l}\text { 3-2 Among all renewable energies in Taiwan, the } \\
\text { cost of solar energy development is the highest. }\end{array}$ \\
\hline & $\begin{array}{l}\text { 3-4 Nuclear power generation is a power generation } \\
\text { system that yields minimal greenhouse gas } \\
\text { emissions. }\end{array}$ \\
\hline & $\begin{array}{l}\text { 3-5 The low cost of renewable energy development } \\
\text { is an advantage of developing renewable energy in } \\
\text { Taiwan. }\end{array}$ \\
\hline & $\begin{array}{l}\text { 3-6 Do you agree to the following ranking regarding } \\
\text { the quantity of greenhouse gas emissions: coal > } \\
\text { petroleum > natural gases? }\end{array}$ \\
\hline & $\begin{array}{l}\text { 3-7 I believe that developing renewable energy can } \\
\text { effectively reduce Taiwan's greenhouse gas } \\
\text { emissions. }\end{array}$ \\
\hline \multirow{3}{*}{\begin{tabular}{l}
\multicolumn{2}{c}{ Index 4 } \\
can communicate \\
about energy \\
issues in \\
meaningful ways
\end{tabular}} & I discuss energy issues with other people. \\
\hline & $\begin{array}{l}\text { 4-2 When I am involved in energy-related } \\
\text { decisions, the opinions of others matter to me. }\end{array}$ \\
\hline & $\begin{array}{l}\text { 4-3 When involved in energy-related decisions, } \\
\text { I attempt to negotiate and coordinate with other } \\
\text { people if our opinions differ. }\end{array}$ \\
\hline \multirow{7}{*}{$\begin{array}{l}\text { Index } 5 \\
\text { is able to make } \\
\text { informed energy } \\
\text { decision }\end{array}$} & $\begin{array}{l}\text { 5-1 Increasing energy use efficiency is } \\
\text { beneficial for Taiwan's energy development. }\end{array}$ \\
\hline & $\begin{array}{l}\text { 5-2 Increasing the ratio of renewable energy use } \\
\text { does not necessarily lead to higher electricity } \\
\text { prices. }\end{array}$ \\
\hline & $\begin{array}{l}5-3 \text { Taiwan's energy costs will not increase } \\
\text { when it reaches the greenhouse gas reduction goal } \\
\text { of } 20 \% \text { in } 2030 \text {. }\end{array}$ \\
\hline & $\begin{array}{l}5-4 \text { I believe that increasing energy prices to } \\
\text { encourage energy savings is an effective way to } \\
\text { reduce energy waste. }\end{array}$ \\
\hline & $\begin{array}{l}5-5 \text { I can judge the rationality of energy } \\
\text { decisions when particular greenhouse gas reduction } \\
\text { goals must be achieved. }\end{array}$ \\
\hline & $\begin{array}{l}\text { 5-6 I am willing to use renewable energy as } \\
\text { power generation fuel even if it generates increased } \\
\text { electricity prices. }\end{array}$ \\
\hline & $\begin{array}{l}\text { 5-7 To achieve greenhouse gas reduction goals, } \\
\text { the ratio of renewable energy use must be increased. }\end{array}$ \\
\hline
\end{tabular}

\section{B. Experiment Design}

We designed an experiment including pret- and post-test to observe the difference of changing energy-literacy between the group experienced only knowledge map of energy and the group experienced all functions of web. Two groups of subjects were invited to join this experiment, both groups got pretest before teaching experiment but only one (we called it as Group II) experienced the role-playing game and decision support of web. Finally, we made a protest of energy-literacy to both groups as Fig. 4. A total of 138 questionnaires were distributed to those subjects and 120 valid copies were recovered at this experiment.

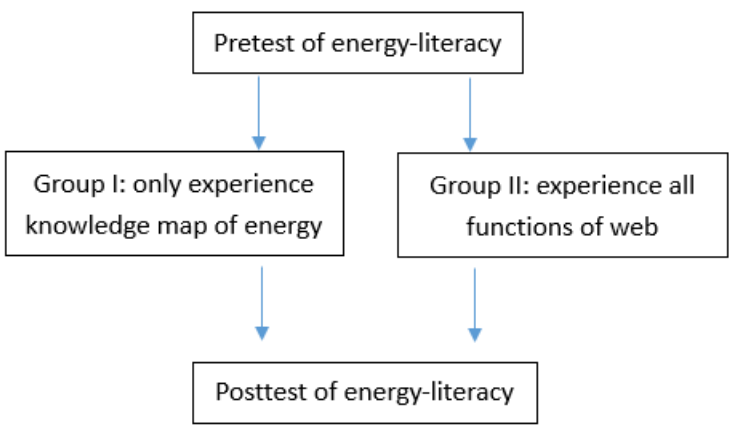

Fig. 4. Teaching experiment of energy. 


\section{P-value Approach}

$P$-value is the probability that the null hypothesis is true in statistical analysis. We used it to determine "likely" or "unlikely" of performances in both groups. If the $P$-value is getting smaller, the difference of two groups is more obvious. Once the $P$-value is less than 0.05 , we judged the performance of two groups is "unlikely.", i.e. we can reject the null hypothesis with an acceptable probability of mistake. When the null hypothesis was rejected, the hypothesis we proposed might be true.

\section{RESUlTS AND DisCUSSION}

\section{A. Performance of Energy-Literacy during Pretest}

The energy-literacy of Group I was at the average of 8.33 during pretest and Group II got an average of 8.92. Then we used the $P$-value approach to verify the "likely" of two groups' energy-literacy. As a result, $P$-value is 0.221 and obvious lager than 0.05 . So we treated the energy-literacy of Group I and Group II before teaching experiment as equal.

\section{B. Effect of Knowledge Map}

The subjects were asked to answer this questionnaire at pre-test and post-test. Results showed that the subjects become more energy-literate after visiting the knowledge map of web (Table II). Index 1 with all "Rise" confirms that knowledge map is able to improve the user's thinking in terms of energy systems. Index 2 is at two different trends. The score of question 2-2 is "No Rise", that means most Taiwanese are already aware of the fact of relying on importing energy. Interestingly, the score of question 2-4 has a "Big Rise". That reveal most Taiwanese don't understand the real energy supply from nuclear. Index 3 with the most significant strongly confirms that the knowledge map is able to improve user's assessing the credibility of information about energy. Index 4 are also rise, confirms that the knowledge map is able to let the uses know how communicate about energy issues in meaningful ways. Overall the knowledge map is useful and using a knowledge map to expand the web's content is indeed necessary for promoting user's energy literacy.

\section{Effect of Role-Playing Game}

Then we carried out a series of hypotheses test to verify the effects of role-playing game and decision support. There are only 9 questions from Table1 being selected to verify the hypothesis of module's function (Table III \& IV).

Role-playing game is not workable in this study (see Table III). Hypothesis-1 was rejected, so the role-playing game can't let users pay more attention to different views and can't change their willing at discussing with people. Hypothesis-2 was rejected, so the role-playing game can't let users consider different views when making their choice of energy policy. Hypothesis-3 was rejected, so the role-playing game can't let users like to negotiate and coordinate with other people when they face different voice on energy policy.

\section{Effect of Decision Support}

Decision support is useful in this study (see Table IV). Statistics showed a two-tailed significance of .043, so
Hypothesis-4 would be true. That means decision support is useful to let user care the renewable energy. Hypothesis-5 with a two-tailed significance of .043 would be also true. Decision support is promising to let user care the dependence on imported energy. But Hypothesis- 6 was rejected. No matter how to explain the increasing expense due to choosing renewable energy, nobody cares. All the following hypothesis 7, 8, and 9 would be true. While thinking the reduction of GHG emission, decision support can be treated as workable.

TABLE II: CHANGES OF ENERGY-LITERACY WITH THE AID OF KNOWLEDGE MAP OF ENERGY

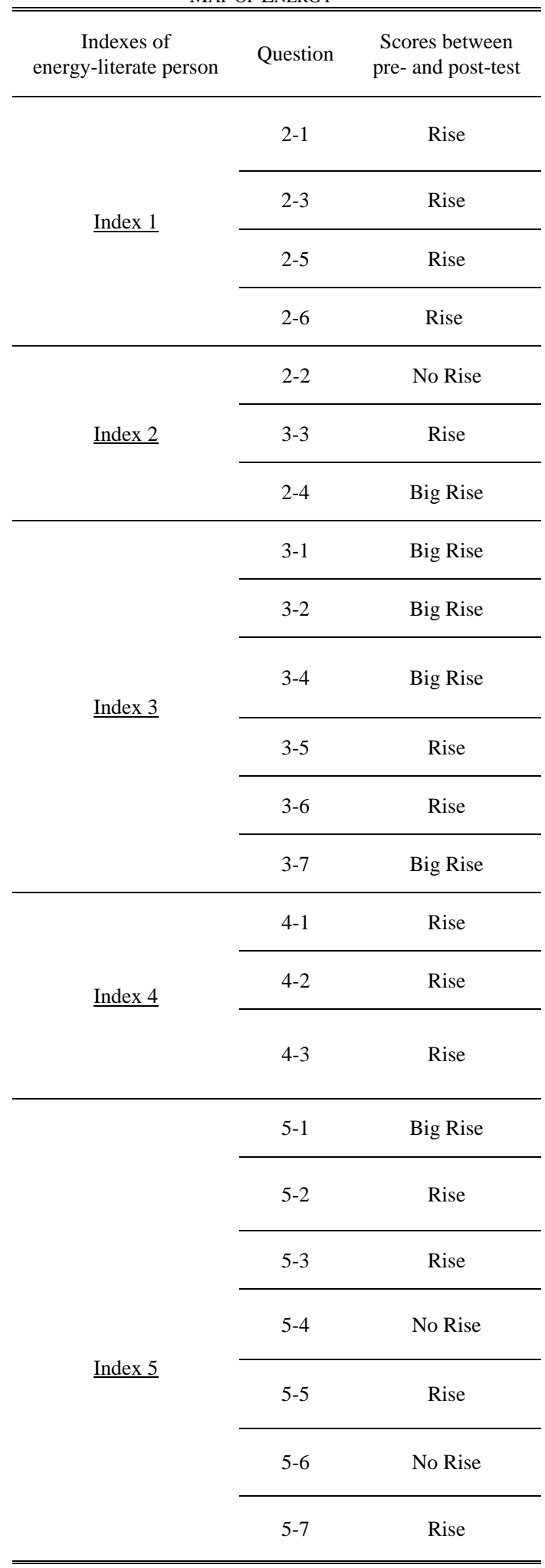


TABLE III: VERIFICATION OF HYPOTHESES FOR ROLE-PLAYING GAME

\begin{tabular}{cccc}
\multirow{2}{*}{ Hypotheses } & \multicolumn{3}{c}{ Question and Statistic analysis } \\
\cline { 2 - 4 } & Tag & P-value & $\begin{array}{l}\text { Difference between } \\
\text { learning groups }\end{array}$ \\
\hline Hypothesis 1 & $4-1$ & .893 & Not significant \\
\hline Hypothesis 2 & $4-2$ & .121 & Not significant \\
\hline Hypothesis 3 & $4-3$ & .121 & Not significant \\
\hline \hline significant $(p<0.05)$ & & &
\end{tabular}

TABLE IV: VERIFICATION OF HYPOTHESES FOR DECISION SUPPORT

\begin{tabular}{cccc} 
& \multicolumn{3}{c}{ Question and Statistic analysis } \\
\cline { 2 - 4 } Hypotheses & Tag & P-value & $\begin{array}{c}\text { Difference between } \\
\text { learning groups }\end{array}$ \\
\hline Hypothesis 4 & $3-3$ & .043 & Significant \\
\hline Hypothesis 5 & $2-2$ & .043 & Significant \\
\hline Hypothesis 6 & $5-2$ & .359 & Not significant \\
\hline Hypothesis 7 & $3-6$ & .014 & Significant \\
\hline Hypothesis 8 & $5-5$ & .016 & Significant \\
\hline Hypothesis 9 & $5-7$ & .004 & Significant \\
\hline Significant $(p<0.05)$ & &
\end{tabular}

\section{CONCLUSION}

Adjusting energy structure is a tough job to have consensus among people because it affects the emission of GHGs, the expense pf electricity, the panic about nuclear simultaneously. Such a dilemma of energy policy not only happens in Taiwan but also everywhere in the world. All we have to do is to let people make an informed decision on the policy of energy. However, most people are ill-prepared to think energy problems due to the cross-disciplinary and complexity of energy issues. Nowadays web's design is going to more interactive and more intelligent. This study adopted the role-playing game to make the process of learning energy issues more interactive and used the decision support to help user making decision more reasonable. Such a web was rarely used in the education of energy issues before. Especially this study used a hypothesis test to verify how IT technologies contribute on a teaching experiment of making energy policy.

Results are interesting and positive to confirm the influence of people who experience this web. We strongly suggest using a knowledge map to expand the web's content when you try to build a web for promoting energy literacy. The only failure in our hypotheses is to over-estimate the possibility of changing people's behavior on communication of public policy. Even with the aid of new IT technology, to speak out the thinking about public policy is still difficult to people. Decision makers need a real talk to vanish the gap not a visual role-playing game. On the contrary, decision support by TEPEM is really workable to let people make an informed decision of energy policy.

The novel AR/VR maybe be promising to enhance the communication of energy policy among strangers in the future. But we have to avoid that people hide their real thinking in a role-playing game and make an irresponsible decision just for fun. So making the web more interactive is good but the users have to feel the responsibility of making decision.

\section{ACKNOWLEDGMENT}

J. C. Chen thanks all students and colleagues participated in this study and appreciated the strong backup from his family.

\section{REFERENCES}

[1] Potential Contribution of Bioenergy to the World's Future Energy Demand, International Energy Agency, 2007.

[2] B. M. Jenkins, "A comment on the optimal sizing of a biomass utilization facility under constant and variable cost scaling," Biomass and Bioenergy, vol. 13, pp. 1-9, 1997.

[3] M. Drozdz, "Polish energy-system modernization," Applied Energy, vol. 76, pp. 267-277, 2003.

[4] S. Iniyan and K. Sumathy, "The application of a Delphi technique in the linear programming optimization of future renewable energy options for India," Biomass \& Bioenergy, vol. 24, pp. 39-50, 2003.

[5] H. R. Becerra-López and P. Golding, "Multi-objective optimization for capacity expansion of regional power-generations systems: Case study of far west Texas," Energy Conversion and Management, vol. 49, pp. 1433-1445, 2008.

[6] Energy literacy: Essential principles and fundamental concepts for energy education. (2012). U.S. Department of Energy (DOE): Washington, DC, USA. [Online]. Available: www.globalchange.gov.

[7] E. S. Geller, "Evaluating energy conservation programs: Is verbal report enough?" Journal of Consumer Research, vol. 8, December, 1981.

[8] L. H. Barrow and J. T. Morrisey, "Energy literacy of ninth-grade students: A comparison between maine and new brunswick," The Journal of Environmental Education, vol. 20, pp. 22-25, 1989.

[9] Americans' Low “Energy IQ:” A Risk to Our Energy Future/Why America Needs a Refresher Course on Energy. National Environmental Education \& Training Foundation, Washington, DC., 2002.

[10] J. DeWaters and S. Powers, "Energy literacy among middle and high school youth," presented at 38th ASEE/IEEE Frontiers in Education Conference, Saratoga Springs, NY, USA, October 22-25, 2008.

[11] S. Sun and Z. Fang, "Portable devices in education in the cyber age," Energy Procedia, vol. 13, pp. 8318-8323, 2011.

[12] Y. M. Huang, Y. T. Lin, and S. C. Cheng, "Effectiveness of a mobile plant learning system in a science curriculum in Taiwanese elementary education," Computer \& Education, vol. 54, pp. 47-58, 2010.

[13] M. Maiese. (October 2003). Negotiation. Beyond Intractability. [Online]. http://www.beyondintractability.org/essay/negotiation.

[14] V. Souchere, L. Millair, J. Echeverria, F. Bousquet, C. Le Page, and M. Etienne, "Co-constructing with stakeholders a role-playing game to initiate collective management of erosive runoff risks at the watershed scale," Environmental Modelling and Software, vol. 25, pp. 1359-1370, 2010.

[15] J. Raiyn, "Developing e-society cognitive platform based on the social agent e-learning goal oriented," Advances in Internet of Things, vol. 1, pp. 1-4, 2011.

[16] Z. P. Yekta and A. N. Nasrabadi, "Concept mapping as an educational strategy to Promote meaningful learning," Journal of Medical Education, vol. 5, pp. 47-50, 2004.

[17] J. D. Novak, "Concept mapping: A useful tool for science education," Journal of Research in Science Teaching, vol. 27, pp. 937-949, 1990.

[18] H. Dubberly, "Using concept maps in product development: preparing to redesign java.sun.com," Exposing the Magic of Design: A Practitioner's Guide to the Methods and Theory of Synthesis, Oxford University Press, 2009.

[19] J. H. Lee and A. Segev, "Knowledge maps for e-learning," Computers \& Education, vol. 59, pp. 353-364, 2012.

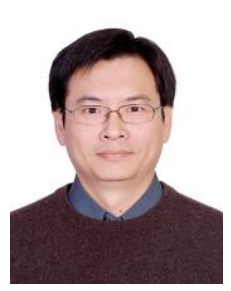

Jeng-Chung Chen was born in Pintung, Taiwan in 1968. He earned his bachelor degree in environmental engineering in 1991 from National Chung Hsing University and master degree in environmental engineering in 1993 from National Chiao Tung University, Taipei, Taiwan. He was qualified and got the license of environmental PE in 1995. He had worked as an engineer for three years and designed four 
domestic wastewater treatment plants, one small solid waste incineration system. Then he moved career to be a teacher at Fooyin University. He finished his Ph.D. in environmental systems in 2002 at National Cheng Kung University. He is currently the director of the department.

Prof. Chen is the member of Institute for Energy, Environment and Sustainable Communities (IEESC). He received the award of outstanding poster in 2013 by Chinese Institute of Environmental Engineering. His design of air purifier wan the silver medal of Taipei Int'l Invention Show and Technomart and the gold medal of Chinese Innovation and Invention Society in 2015 .

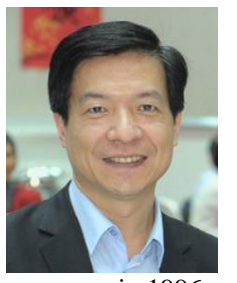

Shin-Cheng Yeh was born in Keelung, Taiwan in 1965. He was educated in Taiwan from primary to higher education. He earned his bachelor degree in civil engineering in 1987 and master degree in environmental engineering in 1992 from National Taiwan University, Taipei, Taiwan. He then attended Cornell University, Ithaca, New York, USA and received his Ph.D. in environmental systems and water resources in 1996

In 2012, he was assigned as the Deputy Minister of Environmental Protection Administration of Taiwan, R.O.C. He was then assigned as the
Minister without Portfolio in late 2014, in charge of coordination of energy, water resources, emergency management, etc. He returned to the university, working as the professor in the Graduate Institute of Environmental Education, National Taiwan Normal University, Taipei, Taiwan in early 2016. He is currently also the director of the institute.

Prof. Yeh was the president of Chinese Society of Environmental Education. He received the Outstanding Teacher in Environmental Protection Award, Taiwan EPA in 2006; Global Outstanding Service to Environmental Education by an Individual, North America Association for Environmental Education in 2014; and The First Class Merit Medal of the Executive Yuan, Taiwan, R.O.C. in 2016

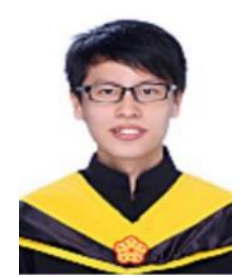

Han Chen was born in Pintung, Taiwan in 1989. He earned his bachelor degree in 2011 and master degree in 2013 in environmental engineering and science from Fooyin University, Kaohsiung, Taiwan. $\mathrm{He}$ is the engineer of Advanced Semiconductor Engineering Inc. Right now he is on the journey of working holiday experience in the Australia. 